\title{
Functional group influences on the reactive azo dye decolorization performance by electrochemical oxidation and electro-Fenton technologies
}

\author{
Izabelle Cristina da Costa Soares ${ }^{1} \cdot$ Djalma Ribeiro da Silva $^{1}$. \\ José Heriberto Oliveira do Nascimento ${ }^{2}$ - Sergi Garcia-Segura ${ }^{1}$. \\ Carlos Alberto Martínez-Huitle ${ }^{1,3}$
}

Received: 27 November 2016 / Accepted: 25 August 2017 /Published online: 7 September 2017

(C) Springer-Verlag GmbH Germany 2017

\begin{abstract}
Electrochemical water treatment technologies are highly promising to achieve complete decolorization of dyebath effluents, as demonstrated by several studies reported in the literature. However, these works are focused on the treatment of one model pollutant and generalize the performances of the processes which are not transposable since they depend on the pollutant treated. Thus, in the present study, we evaluate, for the first time, the influence of different functional groups that modify the dye structure on the electrochemical process decolorization performance. The textile azo dyes Reactive Orange 16, Reactive Violet 4, Reactive Red 228, and Reactive Black 5 have been selected because they present the same molecular basis structure with different functional groups. The results demonstrate that the functional groups that reduce the nucleophilicity of the pollutant hinder the electrophilic attack of electrogenerated hydroxyl radical. Thereby, the overall decolorization efficiency is consequently reduced as well as the decolorization rate. Moreover, the presence of an
\end{abstract}

Responsible editor: Angeles Blanco

Sergi Garcia-Segura

sergigs_87@hotmail.com

Carlos Alberto Martínez-Huitle

carlosmh@quimica.ufrn.br

1 Laboratório de Eletroquímica Ambiental e Aplicada (LEAA), Institute of Chemistry, Federal University of Rio Grande do Norte, Lagoa Nova, CEP, Natal, RN 59078-970, Brazil

2 Departamento de Engenharia Têxtil, Federal University of Rio Grande do Norte, Lagoa Nova, CEP, Natal, RN 59078-970, Brazil

3 National Institute for Alternative Technologies of Detection, Toxicological Evaluation and Removal of Micropollutants and Radioactives (INCT-DATREM), Institute of Chemistry, Unesp, P.O. Box 355, Araraquara, SP 14800-900, Brazil additional chromophore azo bond in the molecule enhances the recalcitrant character of the azo dyes as pollutants. The formation of a larger and more stable conjugated $\pi$ system increases the activation energy required for the electrophyilic attack of ${ }^{\circ} \mathrm{OH}$, affecting the performance of electrochemical technologies on effluent decolorization.

Keywords Wastewater treatment · Electro-Fenton - Reactive azo dyes $\cdot$ Electrochemical advanced oxidation processes · Boron-doped diamond anode

\section{Introduction}

The development of water treatment technologies to decolorize dyestuff effluents is a hot topic of research nowadays due to the several environmental concerns related especially to azo dyes (Nguyen and Juang 2013; Brillas and Martínez-Huitle 2015). These emerging pollutants of concern generate visual pollution due to the coloration of water bodies, even at low concentration. The water coloration reduces the sun irradiation penetration affecting the aquatic ecosystems. Eutrophication and/or odor alteration have been also related to dyed effluents (Thevenon et al. 2011). Furthermore, undesired side effects of several dyes as pollutants are associated to their toxicity, mutagenicity, and suspected carcinogenity (Wang et al. 2010; Couto et al. 2013; Freeman et al. 2013; Florenza et al. 2014). Thus, the treatment of industrial effluents containing azo dyes is of great relevance (UNESCO 2012). However, the high stability of these compounds undermines their effective removal from water bodies by conventional water treatment technologies (Brillas and MartínezHuitle 2015). The numbers are more worrying when it is evaluated as a function of the dye manufacture, which supposes 
more than $7 \times 10^{5}$ tons of annual production. After their usage in dyestuff baths, more than 280,000 tons/year are directly discharged as wastewater effluents. Hence, a simple calculation highlights that about $40 \%$ of the annual production will become a pollution problem (Robinson et al. 2001; Solís et al. 2012).

In consequence, the development of alternative efficient water treatment technologies to deal with this serious environmental issue is of crucial relevance. In this context, the electrochemical advanced oxidation processes (EAOPs) can be considered as a promising technology to reduce the environmental impact of dyeing industry (Panizza and Cerisola 2009; El-Ghenymy et al. 2014; Moreira et al. 2017; Garcia-Segura and Brillas 2017).

Among EAOPS, the electrochemical oxidation (EO) is one of the technologies that has been more thoroughly studied according to the literature (Panizza and Cerisola 2009; ElGhenymy et al. 2014; Martínez-Huitle et al. 2015; Brillas and Martínez-Huitle 2015). The EO process is based on the use of anodic materials of high-over potential of oxygen evolution that yield ${ }^{\bullet} \mathrm{OH}$ as intermediate of the water oxidation from reaction (1) instead of releasing oxygen from reaction (2) (Martínez-Huitle et al. 2015; Moreira et al. 2017).

$\mathrm{M}+\mathrm{H}_{2} \mathrm{O} \rightarrow \mathrm{M}\left({ }^{\bullet} \mathrm{OH}\right)+\mathrm{H}^{+}+\mathrm{e}^{-}$

$\mathrm{H}_{2} \mathrm{O} \rightarrow \S \mathrm{O}_{2}+2 \mathrm{H}^{+}+2 \mathrm{e}^{-}$

where $\mathrm{M}\left({ }^{\bullet} \mathrm{OH}\right)$ represents the adsorbed ${ }^{\bullet} \mathrm{OH}$ onto the anode surface $\mathrm{M}$. Thus, the electrogenerated ${ }^{\bullet} \mathrm{OH}$ acts as mediator on the mineralization of organic pollutants (Rajkumar et al. 2007; Ramírez et al. 2013; Aquino et al. 2014; de Araújo et al. 2015). It is important to stress that differently to other alternative methodologies, EO treatment of actual effluents is reported in recent literature (Tsantaki et al. 2012; Solano et al. 2013; Moreira et al. 2017).

On the other hand, EAOPs based on the Fenton's chemistry arise as new high efficient alternative technologies. The electro-Fenton (EF) process consists on the cathodically generation of hydrogen peroxide from the oxygen reduction (3) onto carbonaceous cathodes (Brillas et al. 2009; GarciaSegura and Brillas 2014). Afterwards, the hydrogen peroxide reacts with catalytic amounts of $\mathrm{Fe}^{2+}$ in solution yielding great amounts of homogeneous ${ }^{\bullet} \mathrm{OH}$ from Fenton's reaction (4). Furthermore, the efficacy of EF can be enhanced by the integration of EO in the same electrochemical cell, which makes this technology highly promissory. As reported by several studies, EF process is able to completely mineralize different kind of pollutants such as pharmaceuticals (El-Ghenymy et al. 2013; Olvera-Vargas et al. 2016), pesticides (García et al. 2014; Iglesias et al. 2015), or dyes (Khataee et al. 2012; Moreira et al. 2013; Thiam et al. 2015) in short times of treatment, just in few hours.

$\mathrm{O}_{2(\mathrm{~g})}+2 \mathrm{H}^{+}+2 e^{-} \rightarrow \mathrm{H}_{2} \mathrm{O}_{2}$
$\mathrm{Fe}^{2+}+\mathrm{H}_{2} \mathrm{O}_{2}+\mathrm{H}^{+} \rightarrow \mathrm{Fe}^{3+}+{ }^{\bullet} \mathrm{OH}+\mathrm{H}_{2} \mathrm{O}$

However, the reported results are focused on the treatment of one azo dye molecule selected as model pollutant and try to generalize the performances of the processes which are not transposable. In the present study, the influence of different functional groups in the dye structure on the electrochemical decolorization performance was evaluated. Four different reactive azo dyes of identical basis structure but different functional groups were selected (see Table 1): Reactive Orange 16 (RO16), Reactive Violet 4 (RV4), Reactive Red 228 (RR228), and Reactive Black 5 (RB5). These dyes are widely used at Brazilian textile industry in different pigmentation methods such as Pad steam, Pad batch, or Pad-dry among others. These processes consume a large volume of water that is discarded after the dyebath containing dyes as pollutants. The main goal pursued herein is to understand how different functional groups affect the decolorization kinetics and the efficiency performances of the EAOPs. From the technological and engineering application point of view, the understanding of the influence of molecular structures on the operational time required to decolorize the industrial effluents to attain the release limits defined by law is of high relevance. These are the challenges inquired by the industry to consider the feasibility of these novel technologies, and no attempts have been published in the literature yet. In this context, the analysis of these results would provide valuable information to better understand the fundamentals of the EAOPs and to clarify the relationship between molecular structure and decolorization performance by means of emerging electrochemical technologies.

\section{Experimental}

\section{Chemicals}

All the azo dyes included in this study (RO16, RV4, RR228, RB5) were supplied by Dystar (Brazil). The characteristics and chemical structures of these azo dyes are summarized in Table 1. The $\mathrm{pH}$ was adjusted prior to the experiences using $\mathrm{H}_{2} \mathrm{SO}_{4}$ or $\mathrm{NaOH}$ of analytical grade supplied by SigmaAldrich. Iron sulfate used as Fenton's catalyst and sodium sulfate used as supporting electrolyte were of analytical grade supplied by Merck. All solutions were prepared with highpurity water obtained from a Millipore Milli-Q system with resistivity $>18 \mathrm{M} \Omega \mathrm{cm}$ at $25^{\circ} \mathrm{C}$.

\section{Electrochemical systems, apparatus, and analytical procedures}

Comparative electrolyses were conducted at bench scale using a monocompartimental electrochemical cell thermostated at 
Table 1 Chemical structure and characteristics of reactive azo dyes treated by electrochemical oxidation and electro-Fenton processes.

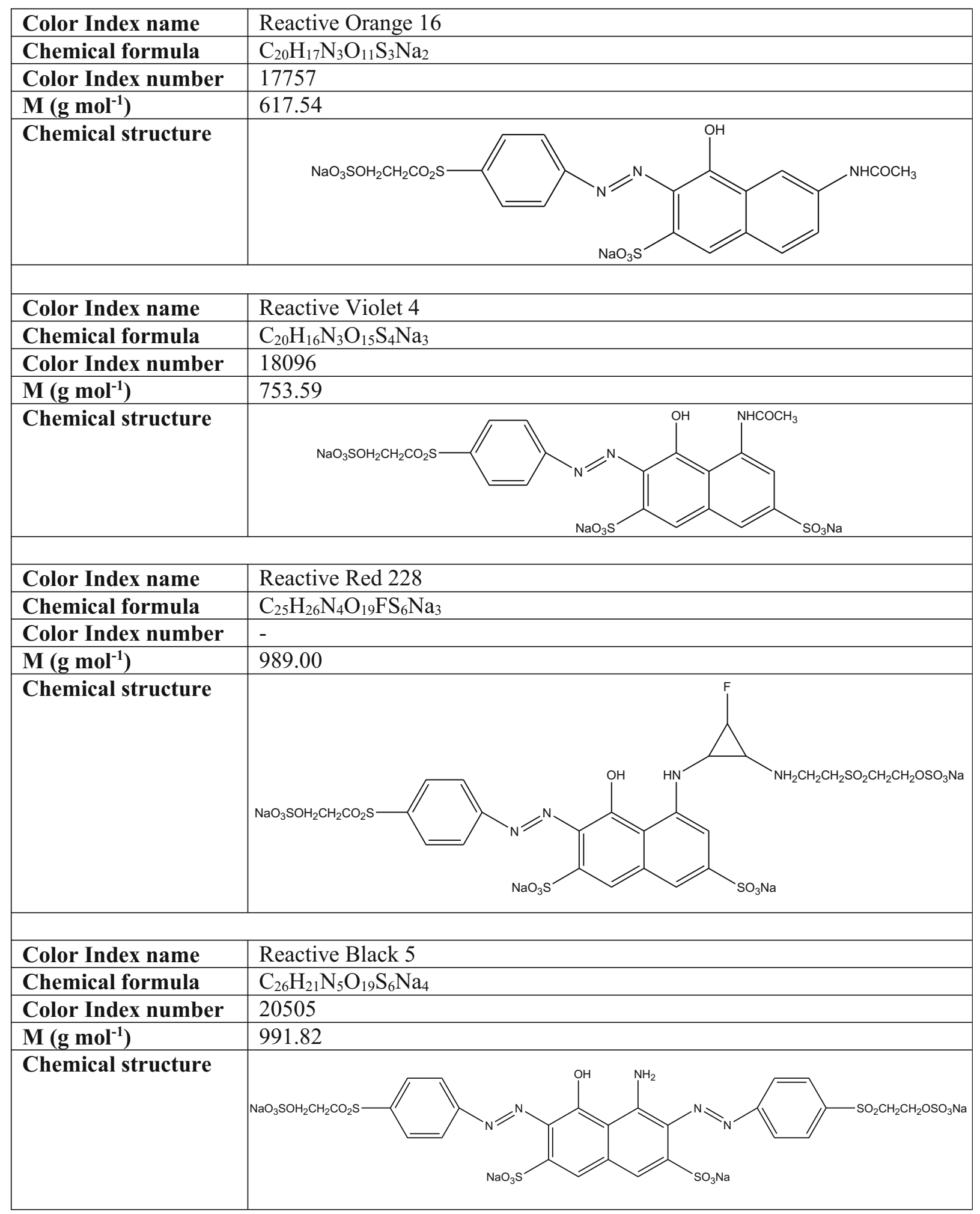

$35{ }^{\circ} \mathrm{C}$. The anodes were either a platinum plate or a BDD plate, while the cathode was a carbon polytetrafluoroethylene air diffusion electrode (ADE) mounted as described elsewhere (dos Santos et al. 2016). The EF experiments were conducted using BDD anodes. The gap distance between electrodes was ca. $1 \mathrm{~cm}$, and the geometric area was $3 \mathrm{~cm}^{2}$ for all electrodes. 
Since the ADE requires a continuous flow of air passing through in order to electrogenerate $\mathrm{H}_{2} \mathrm{O}_{2}$ from reaction (3), an air pump was used to ensure the ADE fed of air at $300 \mathrm{~mL} \mathrm{~min}^{-1}$. A catalytic amount of $0.5 \mathrm{mM}$ of $\mathrm{Fe}^{2+}$ was added when EF experiences were carried out since this is the optimum concentration found in previous works reported in the literature on the treatment of azo dyes by EF (Moreira et al. 2017). The electrodes were reused in all the experiments conducted obtaining reproducible results, which is an indicative of their high durability and reusability.

The $\mathrm{pH}$ of the treated solutions was adjusted at $\mathrm{pH} 3.0$ using a $\mathrm{pH}$-meter Tecnopon mPA-210. Note that $\mathrm{pH} 3.0$ is defined by several authors as optimal operational condition for Fenton and EF processes (Brillas et al. 2009; Moreira et al. 2017). Additionally, the initial $\mathrm{pH}$ of some dyeing bath effluents is acidic (ca. pH 3.0), being similar to the experimental conditions considered herein. The absorbance was determined using an UV-Vis spectrophotometer Analytikjena SPECORD 210 PLUS at the maximum absorptivity of each azo dye: $\lambda_{\max }=429 \mathrm{~nm}$ for RO16, $\lambda_{\max }=544 \mathrm{~nm}$ for RV4, $\lambda_{\max }=527 \mathrm{~nm}$ for RR228, and $\lambda_{\max }=592 \mathrm{~nm}$ for RB5, respectively. From the registered UV-Vis spectra, the percentage of color removal of the solution during the electrochemical treatments was estimated from eq. (5) (Brillas and Martínez-Huitle 2015; dos Santos et al. 2016):

$\%$ Color Removal $=\frac{\mathrm{A}_{0}-\mathrm{A}_{\mathrm{t}}}{\mathrm{A}_{0}} \times 100$

where $A_{0}$ is the initial absorbance and $A_{t}$ the absorbance at the electrolysis treatment time $t$.

\section{Results and discussion}

\section{Decolorization performance of electrochemical advanced oxidation processes}

Figure 1 depicts the electrochemical treatment of $100 \mathrm{~mL}$ of $0.40 \mathrm{mM}$ of RO16 by means of EO and EF. As can be seen, the decolorization performance by EO depends on the anodic material used. While almost complete decolorization is attained after $360 \mathrm{~min}$ of electrolyisis with BDD anode, solely a poor $68.0 \%$ is attained with Pt anode. It is important to stress that although both anodes present a high overpotential of oxygen evolution, the intrinsic electrocatalytic properties on the electrogeneration of $\mathrm{M}\left({ }^{\bullet} \mathrm{OH}\right)$ play a key role on decolorization kinetics (Kapalka et al. 2008; Garcia-Segura et al. 2015). So, the different performance of these anodes is related to the enthalpy of adsorption of the ${ }^{\bullet} \mathrm{OH}$ radicals onto the anode surface. The $\mathrm{M}\left({ }^{\circ} \mathrm{OH}\right)$ is strongly chemisorbed onto the Pt surface, where higher oxides became the main oxidant mediators from reaction (6) (Panizza and Cerisola 2009).

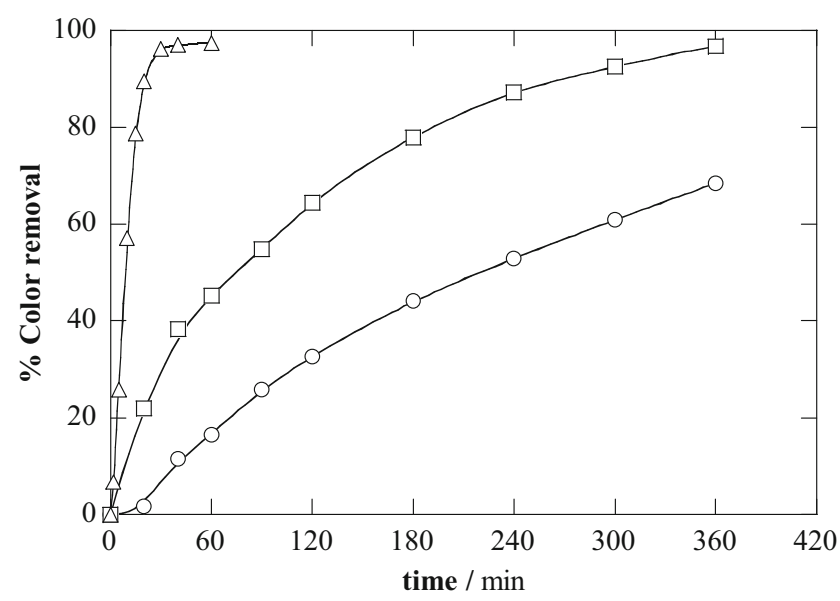

Fig. 1 Evolution of the percentage of color removal with electrolysis time for the treatment of $100 \mathrm{~cm}^{3}$ of $0.400 \mathrm{mM}$ of Reactive Orange 16 solutions in $0.05 \mathrm{M}_{\text {of }} \mathrm{Na}_{2} \mathrm{SO}_{4}$ at $\mathrm{pH} 3.0$ at applied current density of $33.3 \mathrm{~mA} \mathrm{~cm}{ }^{-2}$ by (circle) EO with Pt, (square) EO with BDD and by (triangle) $\mathrm{EF}$ with $0.5 \mathrm{mM}$ of $\mathrm{Fe}^{2+}$

$\mathrm{M}\left({ }^{\bullet} \mathrm{OH}\right) \rightarrow \mathrm{MO}+\mathrm{H}^{+}+\mathrm{e}^{-}$

Then, in this case, these species are less reactive than the physisorbed $\operatorname{BDD}\left({ }^{\bullet} \mathrm{OH}\right)$ electrogenerated on BDD surface, which presents in comparison a higher lability and oxidability. These behaviors are in agreement with the results previously reported in the literature where BDD is considered a "nonactive" anode that favors a complete mineralization of organics (Kapalka et al. 2008; Panizza and Cerisola 2009; Garcia-Segura et al. 2017), whereas Pt is classified as an "active" anode which promotes principally electrochemical conversion reactions mediated by MO species.

While another insight on the EAOP performance on RO16 decolorization depicted in Fig. 1 evidences the decolorization kinetics enhancement by EF approach, achieving complete decolorization after $40 \mathrm{~min}$ of treatment, the estimation of the pseudo-first-order kinetic constants of decolorization $\left(k_{\mathrm{dec}}\right)$ from the absorbance values clearly evidence the difference between these EAOPs. Results showed more than one magnitude order of difference between the values for $\mathrm{EO}$ with $\mathrm{Pt}$ anode, EO with BDD and EF, $4.67 \times 10_{-5} \mathrm{~s}^{-1}\left(R^{2}=0.997\right)$, $1.38 \times 10^{-4} \mathrm{~s}^{-1}\left(R^{2}=0.967\right)$, and $1.92 \times 10^{-3} \mathrm{~s}^{-1}\left(R^{2}=0.991\right)$, respectively. This trend is an indicative of the predominant destruction of the azo bond of $\mathrm{RO} 16$ by the ${ }^{\bullet} \mathrm{OH}$ yielded in the bulk of the solution by Fenton's reaction (Garcia-Segura et al. 2011; Florenza et al. 2014). It is important to remark that these oxidant species, contrarily to the electrogenerated $\mathrm{M}\left({ }^{\bullet} \mathrm{OH}\right)$, are not limited by mass transfer, then, justifying the quicker decolorization achieved during the process (Brillas et al. 2009; Garcia-Segura and Brillas 2014).

Figure 2 shows the decolorization of different reactive azo dyes where decolorization kinetics become greater in the 


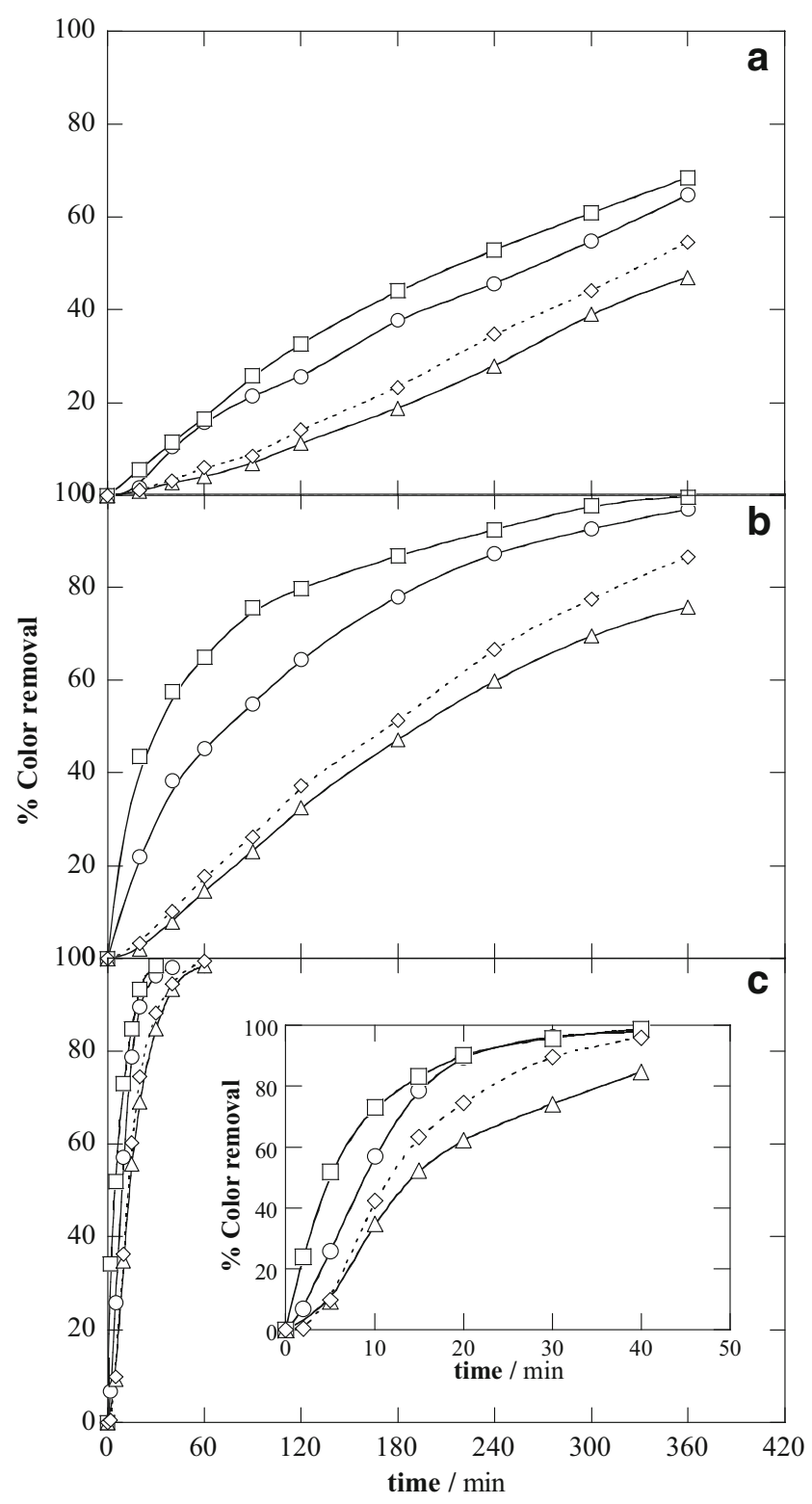

Fig. 2 Decolorization percentage attained during the treatment of $100 \mathrm{~cm}^{3}$ of $0.400 \mathrm{mM}$ Reactive azo dyes solutions in $0.05 \mathrm{M}$ of $\mathrm{Na}_{2} \mathrm{SO}_{4}$ at $\mathrm{pH} 3.0$ at applied current density of $33.3 \mathrm{~mA} \mathrm{~cm}^{-2}$ by a EO with $\mathrm{Pt}$, $\mathbf{b} \mathrm{EO}$ with $\mathrm{BDD}$, and by $\mathbf{c} \mathrm{EF}$ with $0.5 \mathrm{mM}$ of $\mathrm{Fe}^{2+}$. Reactive azo dyes treated: (circle) RO16, (square) RV4, (triangle) RR228, and (diamond) RB5

sequence EO-Pt $<$ EO-BDD $<$ EF, which corresponds to the similar trend observed on the treatment of RO16. Thus, these findings corroborate the higher oxidation ability of $\operatorname{BDD}\left({ }^{\circ} \mathrm{OH}\right)$ than $\mathrm{Pt}\left({ }^{\bullet} \mathrm{OH}\right)$ due to their different electrocatalytic properties (Kapalka et al. 2008; Garcia-Segura et al. 2015; Brillas and Martínez-Huitle 2015; Martínez-Huitle et al. 2015). Apart from that, this trend confirms the predominant role of homogeneous ${ }^{\circ} \mathrm{OH}$ on the decolorization by indirect electrochemical processes based on Fenton's reaction chemistry.

\section{Comparative decolorization: influence of dye structure}

Even though the decolorization percentage removal for the treatment of different reactive azo dyes (see Table 1) under similar experimental conditions follows permanently the sequence EF > EO-BDD > EO-Pt, the decolorization efficiency is completely different when the performance for different dyes is compared for the same electrochemical process. It can be deduced from Fig. 2 that the functional groups and side chains play a key role on the decolorization kinetics, affecting the efficiency of the processes.

It is possible to infer that there are also some differences on the decolorization rate between both RO16 and RV4 (Fig. 2). In the case of EO, this difference is more appreaciable, while a slight difference is observed on the kinetic rate at $E F$ tests. The estimated $k_{\text {dec }}$ are $4.67 \times 10^{-5} \mathrm{~s}^{-1}\left(R^{2}=0.997\right)$ for RO16 and $5.33 \times 10^{-5} \mathrm{~s}^{-1}\left(R^{2}=0.993\right)$ for RV4 at Pt anode by EO; $1.38 \times 10^{-4} \mathrm{~s}^{-1}\left(R^{2}=0.997\right)$ for RO16 and $1.53 \times 10^{-4} \mathrm{~s}^{-1}$ $\left(R^{2}=0.997\right)$ for RV4 at BDD electrode by EO; and $1.92 \times 10^{-3} \mathrm{~s}^{-1}\left(R^{2}=0.992\right)$ for RO16 and $2.10 \times 10^{-3} \mathrm{~s}^{-1}$ $\left(R^{2}=0.996\right)$ for RV4 by EF treatment. These values show relative differences between the estimated constants of about 11,13 , and $16 \%$, respectively. This behavior could be related to the structural differences between RO16 and RV4. Analyzing the structural differences collected in Table 1, we can conclude that the presence of an additional sulfonic functional group (highly electronegative functional group) in RV4 dye with respect to RO16 chemical structure could promote the electrophilic attack of ${ }^{\bullet} \mathrm{OH}$ radical species. The ${ }^{\bullet} \mathrm{OH}$ attack leads to the pollutant hydroxilation and the subsequent cleavage of the azo bond (the cromophore group) (Vasconcelos et al. 2015). In this frame, the enhancement on the decolorization efficiency is directly related to the functional groups and their position in the molecular structure of these dyes (Garcia-Segura et al. 2011; Araújo et al. 2014; Vasconcelos et al. 2015). In fact, this effect is more significant when more clear changes are observed in the chemical structure. As can be seen also in Fig. 2, RO16 and RV4 showed a fast decolorization kinetics in comparison with the RR228 and RB5 dyes, by using EO or EF approaches. An inspection of Table 1 reveals that the basic molecular structure for the four reactive azo dyes is equivalent. However, RR228 presents a longer side chain as functional group, and RB5 has an extra azo bond. In effect, the slower decolorization observed on the treatment of RR228 solutions is related to the ciclopropil side chain of the amino group. Analyzing the chemical structure of RR228, it is evident that the side chain presents electronegative heteroatoms ( $\mathrm{S}, \mathrm{N}$, and $\mathrm{O}$ ) that increase the nucleophilicity of its carbon atoms, directing the attack of oxidant species. Accordingly, the ${ }^{\bullet} \mathrm{OH}$ attack will occur preferently on the side chain atoms reducing the azo bond breakage reaction rate. Another feature is that the high tension of ciclopropil ring also favors the hydroxilation and consequently, this ring opening 
over those reactions that lead to chromophore group fragmentation. This trend is also reflected on the $k_{\mathrm{dec}}$ values: $1.31 \times 10^{-5} \mathrm{~s}^{-1}\left(R^{2}=0.990\right)$ for $\mathrm{EO}$ with $\mathrm{Pt}$ anode, $6.83 \times 10^{-5} \mathrm{~s}^{-1}\left(R^{2}=0.996\right)$ for EO with BDD electrode, and $7.70 \times 10^{-4} \mathrm{~s}^{-1}\left(R^{2}=0.998\right)$ by EF treatment at $33.3 \mathrm{~mA} \mathrm{~cm}{ }^{-2}$. It is important to remark that these values are considerably lower than those estimated for the treatment of RV4 solutions.

On the other hand, the slower kinetics observed on the treatment of RB5 is directly associated to the presence of an additional azo bond as additional chromophore group (GarciaSegura et al. 2011; Vasconcelos et al. 2015). The increase in the number of azo bonds per molecule forms a larger and more stable conjugated $\pi$ system (cf. Table 1 ) becoming greater the activation energy required for the electrophyilic attack of - $\mathrm{OH}$. The requirement of a greater activation energy enhances the recalcitrant character of this pollutant (Garcia-Segura et al. 2011). Consequently, this effect promotes a significant decrease on the decolorization rate independently of the electrochemical treatment used, as depicted in Fig. 2. This assertion is supported by the $k_{\mathrm{dec}}$ values estimated for each one of the treatments used: $1.73 \times 10^{-5} \mathrm{~s}^{-1}\left(R^{2}=0.989\right)$ for EO with $\mathrm{Pt}$ anode, $7.63 \times 10^{-5} \mathrm{~s}^{-1}\left(R^{2}=0.992\right)$ for $\mathrm{EO}$ with BDD electrode, and $1.46 \times 10^{-3} \mathrm{~s}^{-1}\left(R^{2}=0.994\right)$ for EF treatment at $33.3 \mathrm{~mA} \mathrm{~cm}^{-2}$.

Another important feature is that the increase on the recalcitrant character of the target pollutant favors the enhancement of parasitic reactions. The parasitic reactions consume the electrogenerated ${ }^{\bullet} \mathrm{OH}$, therefore avoiding the organic reactions related to the mineralization nor decolorization. Several parasitic reactions are feasible; however, the most common are (i) the oxygen evolution from $\operatorname{BDD}\left({ }^{\bullet} \mathrm{OH}\right)$ by reaction (7), the dimerization of ${ }^{\bullet} \mathrm{OH}$ or $\mathrm{BDD}\left({ }^{\bullet} \mathrm{OH}\right)$ yielding $\mathrm{H}_{2} \mathrm{O}_{2}$ according to reactions (8) and (9), and the formation of hydroperoxyl radical $\left(\mathrm{HO}_{2}{ }^{\bullet}\right)$ from $\mathrm{H}_{2} \mathrm{O}_{2}$ by reactions (10) and (11) (Andrade et al. 2009; Brillas et al. 2009; Özcan and Gençten 2016).

$$
\begin{aligned}
& 2 \mathrm{BDD}\left({ }^{\bullet} \mathrm{OH}\right) \rightarrow 2 \mathrm{BDD}+\mathrm{O}_{2}+2 \mathrm{H}^{+}+2 \mathrm{e}^{-} \\
& 2^{\bullet} \mathrm{OH} \rightarrow \mathrm{H}_{2} \mathrm{O}_{2} \\
& 2 \mathrm{BDD}\left({ }^{\bullet} \mathrm{OH}\right) \rightarrow 2 \mathrm{BDD}+\mathrm{H}_{2} \mathrm{O}_{2} \\
& \mathrm{H}_{2} \mathrm{O}_{2}+\bullet{ }^{\bullet} \mathrm{OH} \rightarrow \mathrm{HO}_{2}^{\bullet}+\mathrm{H}_{2} \mathrm{O} \\
& \mathrm{H}_{2} \mathrm{O}_{2}+\mathrm{BDD}\left({ }^{\bullet} \mathrm{OH}\right) \rightarrow \mathrm{BDD}\left(\mathrm{HO}_{2}^{\bullet}\right)+\mathrm{H}_{2} \mathrm{O}
\end{aligned}
$$

Based on these behaviors, it is evident that the functional groups in the chemical structure of dyes affect the electrochemical treatment performances. The modification of the pollutant nucleophilicity modifies the rate and extension of hydroxilation reactions by ${ }^{\bullet} \mathrm{OH}$ that conducts to solution decolorization. Also, these functional groups contribute to the enhancement of the parasitic reactions and consequently, a diminution of the overall decolorization efficiency of the electrochemical treatment approaches.

\section{Effect of electro-Fenton operational parameters on decolorization}

From the results reported formerly, it can be concluded that EF process decolorizes faster and more efficiently the dyebath solutions than EO approach. Thus, the influence of operational parameters on EF performance has been evaluated. Among operational conditions, the applied current density $(j)$ is the most influential parameter as long as the electrochemical process kinetics depends on the number of electrons circulated through the system (Zhou et al. 2012; Thiam et al. 2015; Fernandes et al. 2016). Figure 3 depicts the decolorization attained vs time at different applied $j$ on the treatment of RO16, RV4, RR228, and RB5. As can be seen in Table 2, an increase on the applied $j$ accelerates the decolorization rate, achieving higher color removal efficiencies in shorter times of treatment. However, the decolorization kinetics depends also on the target pollutant even when $j$ is raised, remaining the sequence unchanged RV4 $<$ RO16 $<$ RB5 $<$ RR228. Thus, the functional groups are an undenieable key parameter that affects the kinetics of the treatment.

A significant increase is achieved when the $j$ raises from 16.6 to $33.3 \mathrm{~mA} \mathrm{~cm}^{-2}$, leading approximately to 3 -folds of difference in all cases. Meanwhile, further increases lead to differences of about 1.2 or 1.5 -folds in $k_{\mathrm{dec}}$ values. This behavior indicates that an increase in $j$ accelerates decolorization kinetics, but it also enhances simultaneously parasitic reactions that consume ${ }^{\bullet} \mathrm{OH}$ and $\operatorname{BDD}\left({ }^{\bullet} \mathrm{OH}\right.$ ) (such reactions (7)-(11)) (Andrade et al. 2009; Brillas et al. 2009; Özcan and Gençten 2016). When the applied $j$ is excesively increased, a great amount of electrogenerated oxidant species are consumed in side reactions limiting the decolorization of solutions. Furthermore, it is possible to infer that there is a decolorization kinetic limit that cannot be exceeded by increasing $j$ once the maximum decolorization rate achievable has been reached (Garcia-Segura et al. 2011). Consequently, the increase of $j$ over this limit only results on the unnecesary rise of the associated energy consumption and the operational cost of EF treatment, as it also occurs with other electrochemical technologies (Barhoumi et al. 2015; Madsen et al. 2015). From the results obtained, the application of $66.6 \mathrm{~mA} \mathrm{~cm}-2$ allows to achieve fast and complete decolorization in shorter times almost identical to $100 \mathrm{~mA} \mathrm{~cm}^{-2}$ with lower energy consumption requeriments and so, a lower cost, being $66.6 \mathrm{~mA} \mathrm{~cm}^{-2}$ defined as the optimal operational condition.

The pollutant concentration in the effluents is a variable of high interest since it defines the operational range of the EF water treatment (Robinson et al. 2001; Solís et al. 2012; Nguyen and Juang 2013; Brillas and Martínez-Huitle 2015). 
Fig. 3 Influence of applied current density on the decolorization of $100 \mathrm{~cm}^{3}$ of $0.40 \mathrm{mM}$ solutions of a RO16, b RV4, $\mathbf{c}$ RR228, and d RB5 by EF with $0.5 \mathrm{mM}$ of $\mathrm{Fe}^{2+}$ at $\mathrm{pH} 3.0$. Applied current density: (circle) $16.6 \mathrm{~mA} \mathrm{~cm}^{-2}$, (square)

$33.3 \mathrm{~mA} \mathrm{~cm}^{-2}$, (triangle)

$66.6 \mathrm{~mA} \mathrm{~cm}^{-2}$, and (diamond) $100 \mathrm{~mA} \mathrm{~cm}^{-2}$

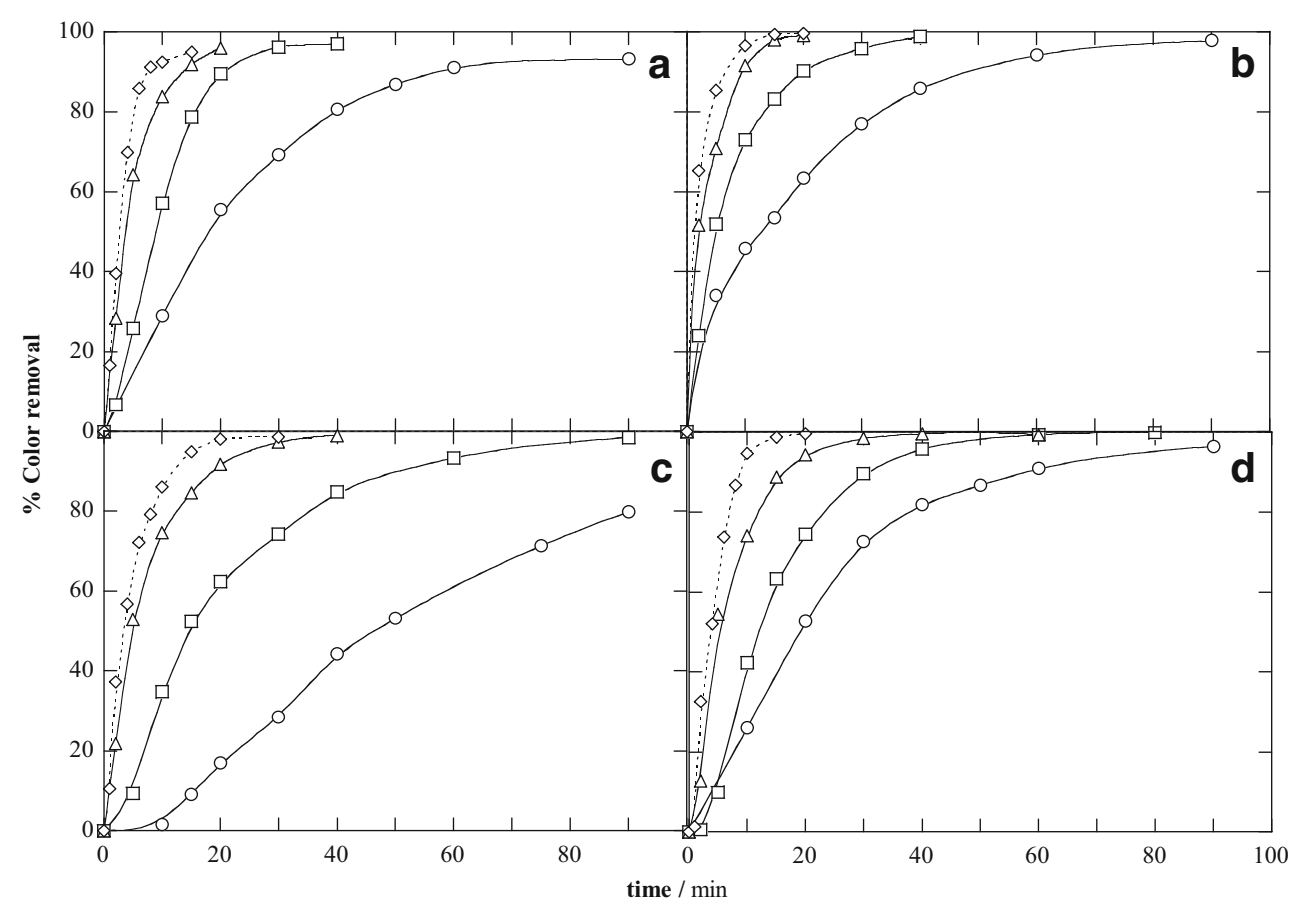

Additionally, the initial concentration of the main pollutant affects the time required to achieve complete decolorization, influencing the overall process efficiency. Figure 4 shows the influence of the initial pollutant concentration for the four treated reactive azo dyes (RO16, RV4, RR228, and RB5) on the decolorization performance of EF treatment at $66.6 \mathrm{~mA} \mathrm{~cm}^{-2}$. The treatment time required to achieve the same color removal percentage rises with the increase of reactive azo dye concentration in solution. This behavior can be ascribed to the fact that the same amount of electrogenerated oxidant species, ${ }^{\bullet} \mathrm{OH}$ and $\operatorname{BDD}\left({ }^{\bullet} \mathrm{OH}\right)$, has to react with greater amounts of organic species (the main pollutant and the byproducts released from its oxidation). Table 3 summirizes the determined $k_{\mathrm{dec}}$ at the different treatment conditions, and it is possible to observe that an increase on the initial concentration of dye favors a decrease on the $k_{\mathrm{dec}}$ value. This behavior is due to the preferential reaction of organics with ${ }^{\bullet} \mathrm{OH}$ and $\operatorname{BDD}\left({ }^{\bullet} \mathrm{OH}\right)$ inhibiting or diminishing the extension of the parasitic reactions (7)-(11) together with the reduction of the competitive oxidation of iron (II) by reactions (12), (13), and (14) (Garcia-Segura et al. 2011).

$$
\begin{aligned}
& \mathrm{Fe}^{2+} \rightarrow \mathrm{Fe}^{3+}+\mathrm{e}^{-} \\
& \mathrm{Fe}^{2+}+\mathrm{BDD}\left({ }^{\bullet} \mathrm{OH}\right) \rightarrow \mathrm{Fe}^{3+}+\mathrm{BDD}+\mathrm{OH}^{-} \\
& \mathrm{Fe}^{2+}+\mathrm{OH} \rightarrow \mathrm{Fe}^{3+}+\mathrm{OH}^{-}
\end{aligned}
$$

From the results reported in Fig. 4, it can be concluded that independently of the initial reactive azo dye concentration, almost complete decolorization is achieved. However, longer treatment times will be required when higher initial concentrations have to be treated. In addition, at higher organic load, an activation time period could be required to initiate the decolorization process. This trend is associated to the fact that the initial hydroxylation reactions under high azo dye

\begin{tabular}{|c|c|c|c|c|}
\hline \multirow[t]{2}{*}{$j / \mathrm{mA} \mathrm{cm}^{-2}$} & \multicolumn{4}{|l|}{$k_{\mathrm{dec}} / \mathrm{s}^{-1}$} \\
\hline & RV4 & RO16 & RB5 & RR228 \\
\hline 16.6 & $7.7 \times 10^{-4}(0.995)$ & $6.8 \times 10^{-4}(0.999)$ & $6.3 \times 10^{-4}(0.991)$ & $3.2 \times 10^{-4}(0.992)$ \\
\hline 33.3 & $2.1 \times 10^{-3}(0.996)$ & $1.9 \times 10^{-3}(0.992)$ & $1.5 \times 10^{-4}(0.994)$ & $7.7 \times 10^{-4}(0.998)$ \\
\hline 66.6 & $4.2 \times 10^{-3}(0.994)$ & $2.7 \times 10^{-3}(0.993)$ & $2.3 \times 10^{-3}(0.999)$ & $1.8 \times 10^{-3}(0.996)$ \\
\hline 100 & $5.4 \times 10^{-3}(0.994)$ & $5.3 \times 10^{-3}(0.994)$ & $4.8 \times 10^{-3}(0.991)$ & $3.3 \times 10^{-3}(0.998)$ \\
\hline
\end{tabular}

Table 2 Estimated pseudo-first order decolorization rates at different applied $j$ on the treatment by electro-Fenton of $0.4 \mathrm{mM}$ reactive azo dye solutions Reactive Violet 4 (RV4), Reactive Orange 16 (RO16), Reactive Black 5 (RB5), and Reactive Red 228 (RR228) 
Fig. 4 Influence of Reactive azo dye initial concentration on the decolorization by EF with $0.5 \mathrm{mM}$ of $\mathrm{Fe}^{2+}$ at $\mathrm{pH} 3.0$ and $j=66.6 \mathrm{~mA} \mathrm{~cm}^{-2}$ of a RO16, b RV4, $\mathbf{c}$ RR228, and d RB5. Initial concentration: (circle) $0.2 \mathrm{mM}$, (square) $0.4 \mathrm{mM}$, (triangle) $0.8 \mathrm{mM}$, and (diamond) $1.2 \mathrm{mM}$

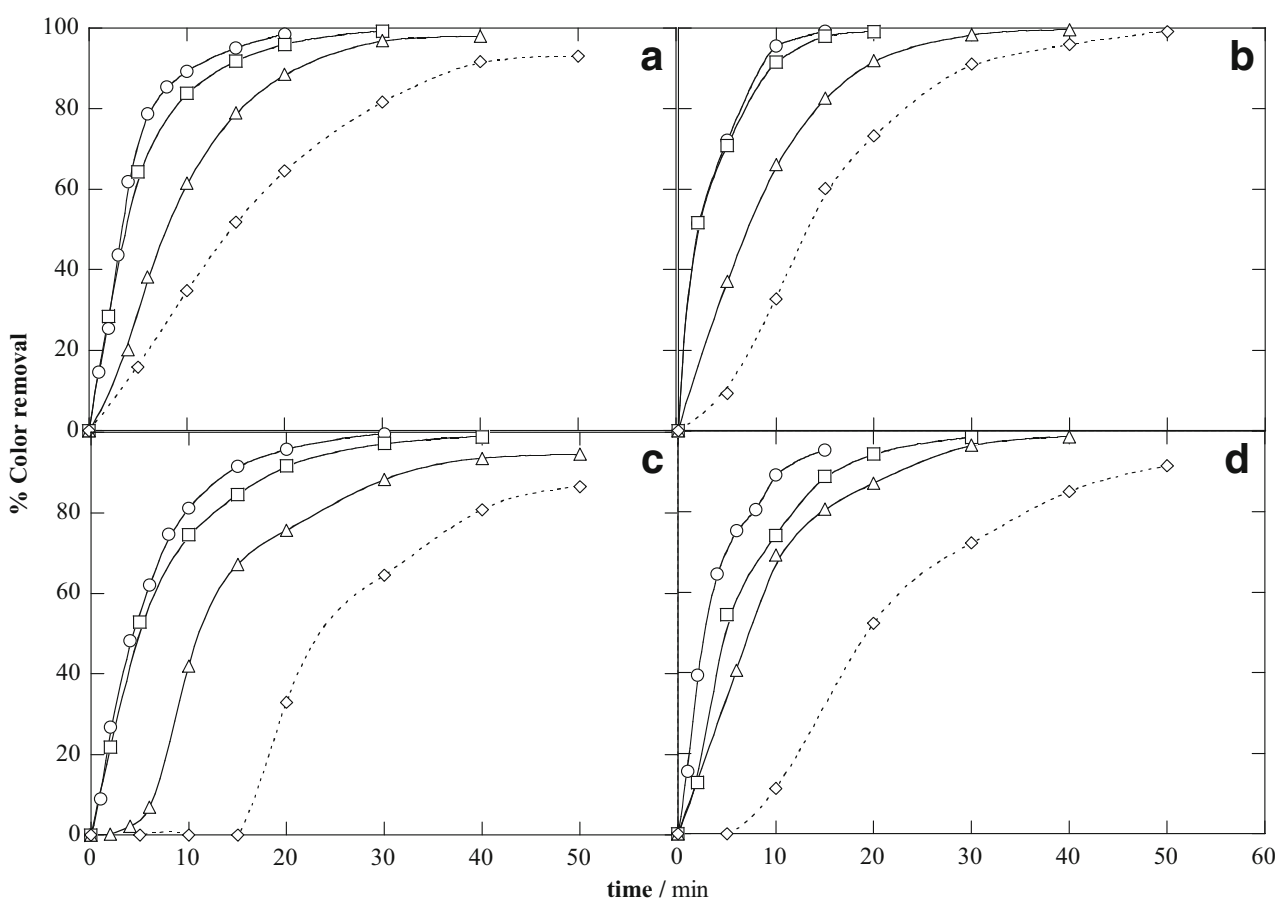

concentration can conduct to the accumulation of colored byproducts in the initial steps rather than to the breakage of the cromophore azo bond that results in decolorization.

Restricting now our analysis to the same initial concentration of azo dye, the relative decolorization kinetics continues following the sequence RV4 $<$ RO16 < RB5 < RR228 due to the influence of functional groups on the recalcitrant character of the treated pollutants.

Noteworthy is to realize the similar $\mathrm{k}_{\mathrm{dec}}$ values of RB5 and RV4 in Table 3 when those are compared in terms of total azo bond concentration (Garcia-Segura et al. 2011). It should be remembered that RV4 and RB5 present exactly the same basic molecular structure (see Table 1) with the difference of an extra azo bond per molecule in RB5. These findings demonstrate the large influence of the number of azo bonds per molecule on their reactivity with ${ }^{\bullet} \mathrm{OH} / \mathrm{BDD}\left({ }^{\bullet} \mathrm{OH}\right)$ and hence, on their decolorization kinetics. Thus, the decolorization rate of mono and diazo dyes could be comparable by means of azo bond concentration rather than in means of azo dye concentration.

\section{Conclusions}

The effectiveness of electrochemical advanced oxidation processes on the decolorization of azo dye solutions has been corroborated in terms of color removal by EO with Pt and BDD anodes as well as by EF process. The results demonstrate that the oxidation power and decolorization kinetics of these electrochemical technologies increased in the sequence EO-Pt $<$ EO-BDD $<$ EF regardless of the reactive azo dye treated. This trend is ascribed to the faster oxidation and higher reactivity of homogeneous • $\mathrm{OH}$ yielded by Fenton's reaction in EF than that the heterogeneous $\mathrm{M}\left({ }^{\bullet} \mathrm{OH}\right)$. The $\mathrm{M}\left({ }^{\bullet} \mathrm{OH}\right)$ adsorbed on the anode surface (Pt or BDD) is kinetically limited by mass

Table 3 Estimated pseudo-first-order decolorization rates at different initial concentration by electro-Fenton approach at $66.6 \mathrm{~mA} \mathrm{~cm}^{-2}$ on the treatment of Reactive Violet 4 (RV4), Reactive Orange 16 (RO16), Reactive Black 5 (RB5), and Reactive Red 228 (RR228)

\begin{tabular}{lllll}
\hline [Reactive dye]/mM & \multicolumn{2}{l}{$k_{\mathrm{dec}} / \mathrm{s}^{-1}$} & & \\
\cline { 2 - 5 } & $\mathrm{RV} 4$ & $\mathrm{RO} 16$ & $\mathrm{RB} 5$ & $\mathrm{R} 228$ \\
\hline 0.2 & $5.4 \times 10^{-3}(0.993)$ & $4.2 \times 10^{-3}(0.985)$ & $2.3 \times 10^{-3}(0.994)$ & $2.7 \times 10^{-3}(0.997)$ \\
0.4 & $4.2 \times 10^{-3}(0.994)$ & $2.7 \times 10^{-3}(0.993)$ & $2.3 \times 10^{-3}(0.999)$ & $1.8 \times 10^{-3}(0.995)$ \\
0.8 & $2.4 \times 10^{-3}(0.995)$ & $2.0 \times 10^{-3}(0.994)$ & $1.8 \times 10^{-3}(0.996)$ & $1.2 \times 10^{-3}(0.983)$ \\
1.2 & $1.4 \times 10^{-3}(0.990)$ & $9.6 \times 10^{-4}(0.991)$ & $8.7 \times 10^{-4}(0.990)$ & $7.2 \times 10^{-4}(0.978)$ \\
\hline
\end{tabular}


transfer. In the case of EO, the obtained results demostrate the superior oxidation power of $\operatorname{BDD}\left({ }^{\bullet} \mathrm{OH}\right)$ than $\mathrm{Pt}\left({ }^{\bullet} \mathrm{OH}\right)$.

Regarding on the effect of the molecular structure, the decolorization kinetics is independent of the electrochemical process used. The decolorization kinetics followed the removal order RV4 > RO16 > RB5 > RR228. The different color removal rate is clearly influenced by the functional groups, which are the main structural difference on the treated reactive azo dyes. These results point out that the modification of the pollutant nucleophilicity affects the extension of the electrophilic attack of $\mathrm{M}\left({ }^{\bullet} \mathrm{OH}\right)$ and ${ }^{\bullet} \mathrm{OH}$. Thereby, an increase in the recalcitrant character of the pollutant (i) increases the activation energy required for the radical attack, (ii) it enhances the parasitic reactions, and (iii) it diminishes consequently the overall decolorization kinetics. Moreover, it has been observed in the case of RB5 that the presence of an additional azo bond per molecule promotes a significant decrease on the decolorization process due to the formation of a larger and more stable conjugated $\pi$ system.

The evaluation of the influence of operational parameters on EF performance demonstrated that an increase in $j$ enhances the decolorization kinetics because of the greater electrogeneration of $\operatorname{BDD}\left({ }^{\bullet} \mathrm{OH}\right)$ and ${ }^{\bullet} \mathrm{OH}$. Nevertheless, the overall decolorization efficiency decreases due to the concomitant increase of parasitic reactions (as kinetic behavior) consuming these radicals in reactions that do not conduct to solution decolorization. On the other hand, the evaluation of the initial concentration of reactive azo dyes in solution demonstrated the wide range of applicability of EF to decolorize dyebath effluents. Even though longer operational times to reach complete decolorization are necessary at higher dye concentrations, no alteration on the decolorization order is attained, confirming that the chemical structure of the dye is a key parameter during its elimination. Finally, it is important to remark that EF approach must be performed at acidic conditions (aproximately $\mathrm{pH} 3.0$ ), and these $\mathrm{pH}$ conditions are present in some effluents when it is generated after dyeing process in the industry; however, alkaline $\mathrm{pH}$ conditions are the most typical circuntances in textile wastewaters; then, the behaviors attained in this study can be different, and consequently, more studies must be done.

Acknowledgements Brazilian financial supports from National Council for Scientific and Technological Development (CNPq-465571/ 2014-0, CNPq-446846/2014-7, and CNPq - 401519/2014-7) and FAPESP (2014/50945-4) are gratefully acknowledged. I.C.C. Soares gratefully acknowledge the $\mathrm{PhD}$ grant awarded from CAPES. S. Garcia-Segura also acknowledges the post-doctoral grant of PNPD/CAPES.

\section{References}

Andrade LS, Tasso T, da Silva DL, Rocha-Filho RC, Bocchi N, Biaggio SR (2009) On the performances of lead dioxide and boron-doped diamond electrodes in the anodic oxidation of simulated wastewater containing the reactive Orange 16 dye. Electrochim Acta 54:2024 2030. https://doi.org/10.1016/j.electacta.2008.08.026

Aquino JM, Rocha-Filho RC, Ruotolo LAM, Bocchi N, Biaggio SR (2014) Electrochemical degradation of a real textile wastewater using $\beta-\mathrm{PbO}_{2}$ and DSA ${ }^{\circledR}$ anodes. Chem Eng J 251:138-145. https://doi.org/10.1016/j.cej.2014.04.032

Araújo CKC, Oliveira GR, Fernandes NS, Zanta CLPS, Castro SSL, da Silva DR, Martínez-Huitle CA (2014) Electrochemical removal of synthetic textile dyes from aqueous solutions using Ti/Pt anode: role of dye structure. Environ Sci Pollut Res 21:9777-9784. https://doi. org/10.1007/s11356-014-2918-4

Barhoumi N, Labiadh L, Oturan MA, Oturan N, Gadri A, Ammar S, Brillas E (2015) Electrochemical mineralization of the antibiotic levofloxacin by electro-Fenton-pyrite process. Chemosphere 141: 250-257. https://doi.org/10.1016/j.chemosphere.2015.08.003

Brillas E, Martínez-Huitle CA (2015) Decontamination of wastewaters containing synthetic organic dyes by electrochemical methods. An updated review. Appl Catal B: Environ 166-167:603-643. https:// doi.org/10.1016/j.apcatb.2014.11.016

Brillas E, Sirés I, Oturan MA (2009) Electro-Fenton process and related electrochemical technologies based on Fenton's reaction chemistry. Chem Rev 109:6570-6631. https://doi.org/10.1021/cr900136g

Couto AC, Ferreira JD, Rosa ACS, Pombo-de-Oliveira MS, Koifman S (2013) Pregnancy, maternal exposure to hair dyes and hair straightening cosmetics, and early age leucemia. Chem Biol Interact 205: 46-52. https://doi.org/10.1016/j.cbi.2013.05.012

de Araújo DM, Sáez C, Martínez-Huitle CA, Cañizares P, Rodrigo MA (2015) Influence of mediated processes on the removal of Rhodamine with conductive-diamond electrochemical oxidation. Appl Catal B Environ 166-167:454 459. https://doi.org/10.1016/j. apcatb.2014.11.038

dos Santos AJ, de Lima MD, da Silva DR, Garcia-Segura S, MartínezHuitle CA (2016) Influence of the water hardness on the performance of electro-Fenton approach: Decolorization and mineralization of Eriochrome black T. Electrochim Acta 208:156-163. https:// doi.org/10.1016/j.electacta.2016.05.015

El-Ghenymy A, Oturan N, Oturan MA, Garrido JA, Cabot PL, Centellas F, Rodríguez RM, Brillas E (2013) Comparative electro-Fenton and UVA photoelectro-Fenton degradation of the antibiotic sulfanilamide using a stirred BDD/air-diffusion tank reactor. Chem Eng J 234:115-123. https://doi.org/10.1016/j.cej.2013.08.080

El-Ghenymy A, Centellas F, Garrido JA, Rodríguez RM, Sirés I, Cabot PL, Brillas E (2014) Decolorization and mineralization of Orange G azo dye solutions by anodic oxidation with a boron-doped diamond anode in divided and undivided tank reactors. Electrochim Acta 130: 568-576. https://doi.org/10.1016/j.electacta.2014.03.066

Fernandes A, Santos D, Pacheco MJ, Ciríaco L, Lopes A (2016) Electrochemical oxidation of humic acid and sanitary landfill leachate: influence of anode material, chloride concentration and current density. Sci Total Environ 541:282-291. https://doi.org/10.1016/j. scitotenv.2015.09.052

Florenza X, Solano AMS, Centellas F, Martínez-Huitle CA, Brillas E, Garcia-Segura S (2014) Degradation of the azo dye acid red 1 by anodic oxidation and indirect electrochemical processes based on Fenton's reaction chemistry. Relationship between decolorization, mineralization and products. Electrochim Acta 142:276-288. https://doi.org/10.1016/j.electacta.2014.07.117

Freeman HS, Jeong E, Claxton LD (2013) Characterization of metabolites of genotoxic 4,40-minoalkoxyazobenzene dyes. Dyes Pigments 99:496-501. https://doi.org/10.1016/j.dyepig.2013.06.001 
García O, Isarain-Chávez E, El-Ghenymy A, Brillas E, PeraltaHernández JM (2014) Degradation of 2,4-D herbicide in a recirculation flow plant with a Pt/air-diffusion and a BDD/BDD cell by electrochemical oxidation and electro-Fenton process. J Electroanal Chem 728:1-9. https://doi.org/10.1016/j.jelechem. 2014.06.019

Garcia-Segura S, Brillas E (2014) Advances in solar photoelectro-Fenton: Decolorization and mineralization of the direct yellow 4 diazo dye using an autonomous solar pre-pilot plant. Electrochim Acta 140: 384-395. https://doi.org/10.1016/j.electacta.2014.04.009

Garcia-Segura S, Brillas E (2017) Applied photoelectrocatalysis on the degradation of organic pollutants in wastewaters. J Photochem Photobio C: Photochem Rev 31:1-35. https://doi.org/10.1016/j. jphotochemrev.2017.01.005

Garcia-Segura S, Centellas F, Arias C, Garrido JA, Rodríguez RM, Cabot PL, Brillas E (2011) Comparative decolorization of monoazo, diazo and triazo dyes by electro-Fenton process. Electrochim Acta 58: 303-311. https://doi.org/10.1016/j.electacta.2011.09.049

Garcia-Segura S, dos Santos EV, Martínez-Huitle CA (2015) Role of sp3/ sp2 ratio on the electrocatalytic properties of boron-doped diamond electrodes: a mini review. Electrochem Commun 59:52-55. https:// doi.org/10.1016/j.elecom.2015.07.002

Garcia-Segura S, Mostafa E, Baltruschat H (2017) Could $\mathrm{NO}_{\mathrm{x}}$ be released during mineralization of pollutants containing nitrogen by hydroxyl radical? Ascertaining the release of $\mathrm{N}$-volatile species. Appl Catal B Environ 207:376-384. https://doi.org/10.1016/j.apcatb.2017.02.046

Iglesias O, Fernández de Dios MA, Tavares T, Sanromán MA, Pazos M (2015) Heterogeneous electro-Fenton treatment: preparation, characterization and performance in groundwater pesticide removal. $\mathrm{J}$ Ind Eng Chem 27:276-282. https://doi.org/10.1016/j.jiec.2014.12. 044

Kapalka A, Fóti G, Comninellis C (2008) Kinetic modelling of the electrochemical mineralization of organic pollutants for wastewater treatment. J Appl Electrochem 38:7-16. https://doi.org/10.1007/ s10800-007-9365-6

Khataee AR, Safarpour M, Naseri A, Zarei M (2012) PhotoelectroFenton/nanophotocatalysis decolorization of three textile dyes mixture: response surfasse modeling and multivariate calibration procedure for simultaneous determination. J Electroanal Chem 672:5362. https://doi.org/10.1016/j.jelechem.2012.03.010

Madsen HT, Søgaard EG, Muff J (2015) Reduction in energy consumption of electrochemical pesticide degradation through combination with membrane filtration. Chem Eng J 276:358-364. https://doi.org/ 10.1016/j.cej.2015.04.098

Martínez-Huitle CA, Rodrigo MA, Sirés I, Scialdone O (2015) Single and coupled electrochemical processes and reactors for the abatement of organic water pollutants: a critical review. Chem Rev 115:1336213407. https://doi.org/10.1021/acs.chemrev.5b00361

Moreira FC, Garcia-Segura S, Vilar VJP, Boaventura RAR, Brillas E (2013) Decolorization and mineralization of sunset yellow FCF azo dye by anodic oxidation, electro-Fenton, UVA photoelectroFenton and solar photoelectro-Fenton processes. Appl Catal B Environ 142-143:877-890. https://doi.org/10.1016/j.apcatb.2013. 03.023

Moreira FC, Boaventura RAR, Brillas E, Vilar VJP (2017) Electrochemical advanced oxidation processes: a review on their application to synthetic and real wastewaters. Appl Catal B Environ 202:217-261. https://doi.org/10.1016/j.apcatb.2016.08.037

Nguyen TA, Juang R-S (2013) Treatment of waters and wastewaters containing sulfur dyes: a review. Chem Eng J 219:109-117. https://doi.org/10.1016/j.cej.2012.12.102

Olvera-Vargas H, Oturan N, Buisson D, Oturan MA (2016) A coupled bio-EF process for mineralization of the pharmaceuticals furosemide and ranitidine: feasibility assessment. Chemosphere 155:606-613. https://doi.org/10.1016/j.chemosphere.2016.04.091

Özcan A, Gençten M (2016) Investigation of acid red 88 oxidation in water by means of electro-Fenton method for water purification. Chemosphere 146:245-252. https://doi.org/10.1016/j. chemosphere.2015.12.013

Panizza M, Cerisola G (2009) Direct and mediated anodic oxidation of organic pollutants. Chem Rev 109:6541-6569. https://doi.org/10. $1021 / \mathrm{cr} 9001319$

Rajkumar D, Song BJ, Kim JG (2007) Electrochemical degradation of reactive blue 19 in chloride medium for the treatment of textile dyeing wastewater with identification of intermediate compounds. Dyes Pigments 72:1-7. https://doi.org/10.1016/j.dyepig.2005.07. 015

Ramírez C, Saldaña A, Hernández B, Acero R, Guerra R, Garcia-Segura S, Brillas E, Peralta-Hernández JM (2013) Electrochemical oxidation of methyl Orange azo dye at pilot flow plant using BDD technology. J Ind Eng Chem 19:571-579. https://doi.org/10.1016/j.jiec. 2012.09.010

Robinson T, McMullan G, Marchant R, Nigam P (2001) Remediation of dyes in textile effluent: a critical review on current treatment technologies with a proposed alternative. Bioresor Technol 77:247-255. https://doi.org/10.1016/S0960-8524(00)00080-8

Solano AMS, de Araújo CKC, de Melo JV, Peralta-Hernandez JM, da Silva DR, Martínez-Huitle CA (2013) Decontamination of real textile industrial effluent by strong oxidant species electrogenerated on diamond electrode: viability and disadvantages of this electrochemical technology. Appl Catal B Environ 130-131:112-120. https:// doi.org/10.1016/j.apcatb.2012.10.023

Solís A, Solís M, Pérez HI, Manjarrez N, Flores M (2012) Microbial decolouration of azo dyes: a review. Process Biochem 47:17231748. https://doi.org/10.1016/j.procbio.2012.08.014

Thevenon F, Graham ND, Herbez A, Wildi W, Poté J (2011) Spatiotemporal distribution of organic and inorganic pollutants from Lake Geneva (Switzerland) reveals strong interacting effects of sewage treatment plant and eutrophication on microbial abundance. Chemosphere 84:609-617. https://doi.org/10.1016/j.chemosphere. 2011.03.051

Thiam A, Sirés I, Centellas F, Cabot PL, Brillas E (2015) Decolorization and mineralization of Allura red $\mathrm{AC}$ dye by solar photoelectronFenton: identification of intermediates. Chemosphere 136:1-8. https://doi.org/10.1016/j.jhazmat.2015.02.050

Tsantaki E, Velegraki T, Katsaounis A, Mantzavinos D (2012) Anodic oxidation of textile dyehouse effluents on boron-doped diamond electrode. J Hazard Mater 207-208:91-96. https://doi.org/10.1016/ j.jhazmat.2011.03.107

UNESCO (2012) The United Nations world water Decelopment report 4, vol. 1. Managing Water Report under Uncertainty and Risk

Vasconcelos VM, Ponce-de-León C, Nava JL, Lanza MRV (2015) Electrochemical degradation of RB-5 dye by anodic oxidation, electro-Fenton and by combining anodic oxidation-electro-Fenton in a filter-press flow cell. J Electroanal Chem 765:179-187. https://doi.org/10.1016/j.jelechem.2015.07.040

Wang Q, Gao F, Yuan X, Li W, Liu A, Jiao K (2010) Electrochemical studies on the binding of a carcinogenic anthraquinone dye, Purpurin (C.I. 58 205) with DNA. Dyes Pigments 84:213-217. https://doi.org/10.1016/j.dyepig.2009.09.004

Zhou M, Tan Q, Wang Q, Jiao Y, Oturan N, Oturan MA (2012) Degradation of organics in reverse osmosis concentrate by electroFenton process. J Hazard Mater 215-216:287-293. https://doi.org/ 10.1016/j.jhazmat.2012.02.070 